\title{
Dinâmica da Reforma Administrativa
}

A EXPERIENCIA BRASILEIRA *

A. FONSECA PIMENTEL

(Ex-funcionário internacional da ONU e da FAO, ex-Subchefe do Gabinete Civil da Presidência da República, exDiretor-Geral do DASP e atual Coordenador do Programa de Assistência Técnica da Fundação Getúlio Vargas em Brasília).

\section{I - HISTÓRICO}

A Segunda Guerra Mundial desencadeou no mundo várias fôrças, que estavam, antes, mais ou menos contidas ou ocultas e passaram, a partir de então, a atuar poderosa, senão mesmo irresistivelmente, na determinação dos próprios destinos da humanidade.

Uma dessas fôrças foi, sem dúvida, o movimento anticolonialista, que em um quarto de século, como se sabe, alterou profundamente o mappa-mundi.

Outra - não sem estreita relação com a que se acaba de mencionar - é a intensa aspiração a uma vida melhor que avassaladoramente se apoderou nas nações do chamado Terceiro Mundo. Foi o que o Presidente Nixon chamou "a revolução das grandes expectativas", ou seja, em nosso entender, a legítima reivindicação dos povos subdesenvolvidos por um lugar ao sol, que nasce, òbviamente, para iluminar e aquecer a todos e não apenas a alguns privilegiados.

Êsse fenômeno está em marcha ascendente e, já a esta altura, irrefreável não só nos países que lograram independência política recentemente, como em sua maioria os africa-

* Trabalho escrito originàriamente em inglês por encomenda das Nações Unidas para um seminário de administração realizado em Londres em 1971. 
nos e asiáticos, mas também em outros, como os latino-americanos, que a conquistaram há cêrca de século e meio.

E que, após a Segunda Guerra Mundial, duas coisas se tornaram ofuscantemente claras para tais nações, a saber:

a) que o subdesenvolvimento significa, em última análise, ampla ou extensa dependência econômica e, com tal dependência econômica, não pode existir verdadeira independência política, como magistralmente o ensinava há quase um século o sociólogo francês Émile Durkheim; ${ }^{1}$

b) que o subdesenvolvimento, diversamente do que se pensava ou presumia até há pouco, não constitui fatalidade étnica ou geográfica, revelando-se, antes, removivel em maior ou menor escala, dentro dos recursos ou potencialidades à disposição de cada povo e de acôrdo com esquema de mais equitativa distribuição da riqueza entre as nações.

Daí haver a Carta de São Francisco inscrito como objetivos ou finalidades das Nações Unidas "promover o progresso social e elevar o nível de vida dentro de um conceito mais amplo de liberdade" e "empregar um mecanismo internacional para promover o progresso ecơnomico e social de todos os povos".

E daí, outrossim, haver Sua Santidade o Papa Paulo VI declarado, em documento memorável, que "o novo nome da paz é desenvolvimento." 2

Entretanto, desenvolvimento acelerado, em têrmos de umas poucas décadas e não de séculos, como o exige a atual conjuntura mundial, requer elevada eficiência governamental, pois o Estado, em nossos dias, há de ser, pelas suas proporções e pelas históricas responsabilidades que assumiu, o principal fator ou promotor do progresso nacional. Isso é, òbviamente, tanto mais verdadeiro quanto maior fôr o grau de subdesenvolvimento de um povo.

Daí, por outro lado, a preocupação e os esforços dos povos subdesenvolvidos, em geral, no sentido de se aparelharem para aumentar o ritmo de seu desenvolvimento, mediante, entre outras medidas igualmente necessárias, ampla e profunda reforma administrativa que torne mais eficiente e expedita a ação

1 La División del Trabajo Social, p. 4, Daniel Jorro, Editor, Madrid.

2 Lettre Encyclique de Sa Sainteté le Pape Paul VI sur le dévéloppement des peuples, 76, Typographie Polyglotte Vaticane, $\mathrm{s} / \mathrm{d}$. 
estatal com êsse objetivo, o qual se converteu em verdadeiro imperativo categórico da paz social e internacional em nosso tempo, como tivemos a oportunidade de demonstrar em obra que publicamos recentemente, a propósito do 25 \% aniversário das Nações Unidas. ${ }^{3}$

No Brasil essa preocupação teve início logo após o término do conflito que ensangüentou o mundo de 1939 a 1945.

E em 1951 já o Presidente Vargas designava uma Comissão Interpartidária para levar a efeito uma análise e investigação com vistas a ampla e profunda reforma da administração brasileira. Apesar de concluídos os estudos, não lograram êles aplicação prática, como se sabe, em virtude, entre outros motivos de menor monta, da grave crise política que abalou a nação em agôsto de 1954 e da qual resultou, inclusive, o próprio suicídio do Presidente.

Nos governos subseqüentes, dos Presidente Café Filho, Juscelino Kubitschek e Jânio Quadros, não houve oportunidade para estudos detidos a respeito da matéria: no primeiro e terceiro, pela sua curta duração, e no segundo, pelo próprio temperamento do Presidente Kubitschek, homem pouco interessado nos problemas de natureza administrativa e empenhado na obra substantiva de seu govêrno, de que resultou, entre outros empreendimentos, a construção de Brasilia e a interiorização da capital, sonho secular de boa parte dos brasileiros.

Isso não obstante, fôrça é reconhecer que o Presidente Kubitschek designou duas comissões - a Comissão de Simplificação Burocrática (COSB) e a Comissão de Estudos e Projetos Administrativos (CEPA) - para estudar a melhoria dos padrões de desempenho da administração brasileira. E dos estudos dessas comissões resultou a criação dos Ministérios das Minas e Energia e do Comércio e da Indústria.

Assim, sòmente no Govêrno João Goulart voltaria a reforma administrativa a ser novamente cogitada em profundidade.

Em 1962, em conseqüência, inclusive, de estudo que o autor dêste artigo lhe apresentou, na qualidade de Diretor-Geral do então Departamento Administrativo do Serviço Público (DASP), o Presidente Goulart nomeou, com efeito, um Ministro Extraordinário para a Reforma Administrativa, com a incumbência de elaborar, no prazo de um ano, mediante a colaboração

3 A. Fonseca Pimentel, A Paz e o Pão - Desafio às Nações Unidas, 2ạ ed., Fundação Getúlio Vargas, Rio de Janeiro, GB., 1971. 
de uma equipe de técnicos qualificados, os projetos básicos a respeito.

Em fins de 1963, tais projetos eram remetidos à consideração do Presidente, que os encaminhou ao Congresso Nacional para exame e votação.

Poucos meses após, contudo, a crise política de 1964, com a conseqüente deposição do Presidente e séria comoção no Congresso, paralisou, mais uma vez, os estudos da Reforma, impedindo a sua promulgação.

Esta sòmente veio a se consubstanciar, em pleno regime revolucionário, pelo Decreto-lei $n \div 200$, de 25 de fevereiro de 1967, do Presidente Castello Branco, às vésperas do término de seu mandato e da transmissão do poder ao seu sucessor. ${ }^{4}$

\section{II - LINHAS GERAIS DA REFORMA}

Segundo o Decreto-lei n? 200, de 1967, a administração federal compreende 16 Ministérios, a saber:

1) Ministério da Justiça;

2) Ministério das Relações Exteriores;

3) Ministério do Planejamento e Coordenação Geral;

4) Ministério da Fazenda;

5) Ministério dos Transportes;

6) Ministério da Agricultura;

7) Ministério da Indústria e do Comércio;

8) Ministério das Minas e Energia;

9) Ministério do Interior;

10) Ministério da Educação e Cultura;

11) Ministério do Trabalho e Previdência Social;

12) Ministério da Saúde;

13) Ministério das Comunicações

14) Ministério da Marinha;

15) Ministério do Exército;

16) Ministério da Aeronáutica. ${ }^{5}$

4 O Decreto-lei no 200 já foi modificado várias vêzes, a saber: pelas Leis $n \div 5.396$, de 26-2-1968, no 5.456, de 25-6-1968, e $n \div 5.535$, de 20-9-1968; pelos Decretos-leis $n$ ? 900 , de 29-9-69, n? 991, de 21-10-1969, e n? 1.093, de 17-3-1970.

5 Bàsicamente, essa distribuição por ministérios é a que estava prevista no projeto da Reforma Administrativa de 1963, sob a direçăo do Mivista no projeto da Reforma Administrativa de. 1963, sob a direça feliz, em nosso entender - foi a substituição do Ministério da Ciência e Tecnolog pelo do Planejamento e Coordenação Geral. 
Como é do gôsto do brasileiro, a distribuição dos assuntos pelos diversos Ministérios guarda certa sistemática e coerência.

Os dois primeiros cuidam da política, interna e externa.

O terceiro, com a ressalva feita na nota ${ }^{5}$, apresenta posição singular.

O quarto, quinto, sexto, sétimo, oitavo e nono tratam das finanças e da produção, lato sensu, ou, em outras palavras, da política econômica e financeira do Govêrno.

O décimo, décimo-primeiro, décimo-segundo e décimo-terceiro estão ligados, direta ou indiretamente, à política social.

$E$, finalmente, o décimo-quarto, décimo-quinto e décimosexto se ocupam, juntamente com o Ministério da Justiça e, em parte, com a colaboração do Ministério das Comunicações, da segurança interna e externa.

Além dos Ministérios e seus órgãos integrantes, compreende, ainda, a administração federal os seguintes tipos de órgão da administração indireta:

a) Autarquia - o serviço autônomo, criado por lei, com personalidade jurídica, patrimônio e receita próprios, para executar atividades típicas da administração pública, que requeiram, para seu melhor funcionamento, gestão administrativa e financeira descentralizada.

b) Emprêsa pública - a entidade dotada de personalidade jurídica de direito privado, com patrimônio próprio e capital exclusivo da União, criada por lei para a exploração de atividade econômica que o Govêrno seja levado a exercer por fôrça de contingência ou de conveniência administrativa, podendo revestir-se de qualquer das formas admitidas em direito.

c) Sociedade de economia mista - a entidade dotada de personalidade jurídica de direito privado, criada por lei para a exploração de atividade econômica, sob a forma de sociedade anônima, cujas ações com direito a voto pertençam em sua maioria à União ou a entidade da Administração Indireta.

Os princípios fundamentais a que, segundo a Reforma, deverão obedecer as atividades da administração federal são:

I - Planejamento;

II - Coordenação;

III - Descentralização; 


\section{IV - Delegação de competência;}

\section{V - Contrôle.}

Além de outras - que, a critério do Govêrno, necessitem de coordenação central - serão organizadas em sistema as seguintes atividades auxiliares da administração federal: pessoal, orçamento, estatística, administração financeira, contabilidade e auditoria, serviços gerais.

Ocupa-se, outrossim, a Reforma, com preeminência, de importantes normas sôbre a administração financeira e contabilidade e sôbre a administração de pessoal.

órgão central da primeira é a Inspetoria-Geral de Finanças do Ministério da Fazenda, que coordena as atividades de tôdas as suas congêneres dos demais ministérios e órgãos subordinados diretamente à Presidência da República.

E órgão central da última é o Departamento Administrativo do Pessoal Civil (DASP), que coordena as atividades dos órgãos de pessoal da administração direta e autárquica.

No que concerne às atividades de planejamento, constituem elas atribuição específica do Ministério do Planejamento e Coordenação Geral, com a colaboração das Secretarias-Gerais dos ministérios.

Título especial, por outro lado, merecedor de realce, são as normas específicas relativas a licitações para compras, obras, serviços e alienações.

Eis, em suas linhas gerais, a Reforma Administrativa Brasileira, decretada pelo Govêrno Revolucionário em 1967 e, ainda, em fase de implementação.

\section{III - A DINĀMICA DA REFORMA}

Isso pôsto, cumpre lembrar que é mais fácil promulgar ou decretar uma reforma do que implementá-la efetivamente na prática.

Assim a Reforma Administrativa Brasileira, decorridos quatro anos de sua decretação, ainda não se acha plenamente em vigor. Antes pelo contrário.

Isso se deve, em parte, às crises políticas que o País ainda vem sofrendo, notadamente a de 13 de dezembro de 1968, de que resultou o fechamento do Congresso Nacional por quase um ano, e a de 31 de agôsto de 1969, ocasionada pela enfermidade do Presidente Costa e Silva, com o seu conseqüente 
afastamento das funções presidenciais e, finalmente, a sua morte, em dezembro do mesmo ano.

Mas se deve, sobretudo, à ausência de uma mentalidade verdadeiramente reformista em vários setores da administração e, mesmo, a resistências obstinadas à Reforma em outros setores. Pois, como também se sabe, em matéria de reformas é mais fácil mudar estruturas e programas do que mudar mentalidades.

Daí as dificuldades com que o atual Govêrno Brasileiro, instalado a 31 de outubro de 1969, está enfrentando para prosseguir na implantação da Reforma, não obstante as suas reiteradas manifestações de propósito, nesse sentido.

O Decreto-lei nọ 200, de 1967, prevê (art. 147) para a implantação da Reforma, se necessário, a nomeação de um Ministro Extraordinário que se dedicasse exclusivamente à tarefa, o que, em nosso entender, seria a melhor solução.

O govêrno anterior preferiu, porém, na forma também do citado art. 147, conferir ao Ministro do Planejamento e Coordenação Geral a incumbência de levar a Reforma a efeito, para o que se estabeleceu naquela Secretaria de Estado um Escritório da Reforma Administrativa (E.R.A.).

O atual Govêrno não quis ou não pôde alterar essa estratégia no trato do problema, a qual continua sendo seguida.

Decorrido ano e meio da instalação do Govêrno, os progressos realizados na implantação da Reforma ainda se revelavam escassos, pois além das diifculdades acima apontadas, não lograra o E.R.A. aparelhar-se devidamente para a importante tarefa que Ihe foi atribuída.

Com vistas a contornar essas dificuldades, em março do corrente ano o Ministro do Planejamento e Coordenação Geral celebrou com a Fundação Getúlio Vargas um convênio a vigorar por três anos, a fim de aquela Fundação prestar ao E.R.A. assistência técnica na implantação da Reforma.

Em linhas gerais, o convênio celebrado prevê o seguinte:

a) a assistência técnica será prestada, de preferência, para implementação e/ou execução de projetos específicos de Reforma. Administrativa, selecionados e indicados pelo Ministério do Planejamento e Coordenação Geral e aceitos pela Fundação Getúlio Vargas;

b) para êsse fim, exercerá a Fundação as atribuições que Ihe forem atribuídas pelo E.R.A., mediante troca de correspon- 
dência em que serão estipuladas as condições especificas de cada projeto, obedecida a orientação geral da Reforma, privativa do Ministério do Planejamento e Coordenação Geral;

c) a Fundação Getúlio Vargas organizará uma "Coordenação da Assistência Técnica para a Reforma Administrativa", custeada com recursos fornecidos pelo Ministério do Planejamento e Coordenação Geral e dirigida por um Coordenador, que deverá manter permanente articulação com o Diretor-Geral do E.R.A.;

d) os projetos específicos serão igualmente custeados pelo Ministério do Planejamento e Coordenação Geral, segundo o que fôr estipulado em cada caso, acrescentando-se ao valor de cada projeto $25 \%$ a favor da Fundação Getúlio Vargas.

Já se estabeleceu o mecanismo previsto e o convênio já se acha em plena fase de cumprimento.

A èstratégia básica seguida, de comum acôrdo entre a Fundação e o E.R.A., pode assim se resumir:

a) na impošsibilidade, material e psicológica, da implantação simultânea da Reforma em tôda a administração, adotouse o critério de implantá-la em áreas ou órgãos determinados;

b) a escolha dessas áreas ou órgãos recairá naqueles que maior e mais expedito interêsse demonstrarem pela Reforma, procurando o E.R.A. e a Fundação Getúlio Vargas para êsse fim, partindo-se do pressuposto de que a Reforma - à semelhança do tratamento médico a um paciente - deve ser, de preferência, desejada e não imposta de viva fôrça;

c) com a sua implantação, pela forma mais completa $e$ perfeita possivel, em tais áreas ou órgãos, espera-se formar "ilhas" reformistas capazes de suscitar, pelo exemplo, o aparecimento de outras, em salutar reação em cadeia através de tôda a administração;

d) por meio de seminários intensivos, preparados e ministrados pela Fundação Getúlio Vargas, espera-se, outrossim, transformar substancialmente a mentalidade das classes dirigentes da administração em relação à Reforma;

e) finalmente, pretende-se habilitar tècnicamente, mediante treinamento sistemático e também intensivo, todos aquêles que, de um modo ou de outro, deverão participar da implantação da Reforma.

Nos têrmos do convênio assinado e de acôrdo com a estratégia acima sintèticamente exposta em seus aspectos prin- 
cipais, presta a Fundação Getúlio Vargas, no momento, por intermédio do E.R.A., assistência técnica para a reorganização e reforma administrativa dos Ministérios da Agricultura, do Trabalho e Previdência Social, da Aeronáutica, das Relações Exteriores, do Exército, do Departamento de Polícia Federal e de mais de vinte outros órgãos da administração federal.

Constituem finalidades precípuas da Reforma, entre outras e além da reorganização das estruturas básicas da administração, segundo o próprio Diretor-Geral do E.R.A.:

\section{“1. ORIENTAÇÃO PARA O DESENVOLVIMENTO}

Melhorar a execução dos programas de govêrno, eliminando os obstáculos institucionais à implementação dos projetos prioritários.

\section{ORIENTAÇÃO PARA O PÚBLICO}

Melhorar a qualidade do atendimento ao público, aperfeiçoando o sistema de relações públicas e reduzindo o formalismo para liberar os cidadãos de entraves e demoras na solução de assuntos de seu interêsse.

\section{DESENVOLVIMENTO DOS RECURSOS HUMANOS}

Conhecer as necessidades específicas de desenvolvimento dos recursos humanos da administração pública, em função das demandas qualitativa e quantitativa geradas pelos objetivos e programas prioritários de desenvolvimento sócio-econômico do País, formular e executar programas de elevação do nível educacional e técnico-profissional dos servidores para atender àquelas necessidades, em articulação com o sistema educacional e com o de incentivos ao pessoal.

\section{FORTALECIMENTO DOS SISTEMAS DE PLANEJAMENTO E ORÇAMENTO}

Aperfeiçoar a formulação, a execução e o acompanhamento dos planos, programas e projetos, bem como do orçamento-programa, adequando as SecretariasGerais às funções de planejamento e orçamento que Ihes são atribuídas pela legislação da Reforma Administrativa. 
5. INTEGRAÇÃO PERMANENTE DA REFORMA ADMINISTRATIVA NO PLANEJAMENTO

Tratar de forma integrada e equilibrada os aspectos substantivos e institucionais na elaboração e execução de planos, programas e projetos, eliminando as barreiras de comunicação interdisciplinar e o conceito de reforma administrativa em têrmos temporários e paralelos, e assegurando a manutenção permanente e articulada do planejamento substantivo com o planejamento institucional, de modo que a máquina administrativa esteja sempre sintonizada com as necessidades de execução eficaz e eficiente dos programas e projetos

- prioritários de desenvolvimento sócio-econômico do Brasil.

6. FORTALECIMENTO DA DIREÇÃO SUPERIOR

Concentrar os órgãos de direção superior nas funções de administração das atividades específicas e auxiliares, através do planejamento, supervisão, orientação, coordenação e contrôle da execução, liberando-os das rotinas de execução e das tarefas de mera formalização de atos administrativos.

\section{FORTALECIMENTO DA COORDENAÇAO}

Incrementar e sistematizar as atividades de coordenação dos programas de govêrno através da atuação das chefias individuais; da realização sistemática de reuniões de chefias; da instituição e funcionamento de comissões de coordenação; de consultas e entendimentos entre setores interessados antes da submissão de assuntos a decisão superior; da articulação de órgãos que operam na mesma área geográfica, com o objetivo de assegurar a programação e execução integrada dos serviços federais.

8. DESCENTRALIZAÇÃO ADMINISTRATIVA Descentralizar dentro dos quadros da Administração Federal, distinguindo-se claramente o nível de direção do de execução; descentralizar para as unidades federadas, quando estejam devidamente aparelhadas e mediante convênio; descentralizar para a órbita privada, mediante contratos e concessões; descentralizar 
através de delegação de competência, com o objetivo de assegurar maior rapidez e objetividade às decisões, situando-as nas proximidades dos fatos, pessoas ou problemas a atender.

\section{SISTEMATIZAÇÃO DO CONTRÔLE DE PROGRAMAS E NORMAS}

Sistematizar o contrôle, pela chefia competente, da execução dos programas e da observância das normas que governam a atividade do órgão controlado; o contrôle, pelos órgãos próprios de cada sistema, da observância das normas gerais que regulam o exercício das atividades auxiliares; o contrôle da aplicação dos dinheiros públicos e da guarda dos bens da União pelos órgãos próprios do sistema de contabilidade e auditoria.

10. RACIONALIZAÇÃO DO TRABALHO ADMINISTRATIVO

Racionalizar o trabalho mediante a adequação de estruturas organizacionais às necessidades dos programas de govêrno, bem como a simplificação de processos e supressão de contrôles que se evidenciem como puramente formais, ou cujo custo seja evidentemente superior ao risco, tendo em vista acelerar e tornar mais econômica e eficaz a execução dos projetos prioritários de desenvolvimento, e também melhorar e abreviar a prestação de serviços ao público.

11. INFLUIÇÃO NOS FATÔRES DE PRODUTIVIDADE

Aumentar através de pesquisas o conhecimento sistemático sôbre os fatôres associados à produtividade na execução de programas e projetos prioritários de desenvolvimento, principalmente dos fatôres suscetíveis de influência a curto e médio prazos.

\section{INFLUIÇÃO NO COMPORTAMENTO ADMINISTRATIVO}

Aumentar através de pesquisas o conhecimento sistemático sôbre o comportamento administrativo brasileiro, em função de fatôres políticos, sociais, econômicos, 
culturais e outros, tendo em vista traçar diretrizes e contribuir para o desenvolvimento do sistema administrativo em têrmos globais a longo prazo, em correlação com o desenvolvimento que se verificar nos outros sistemas a que se vinculam os mencionados fatôres."

Por outro lado, os critérios estabelecidos pelo próprio Diretor-Geral do E.R.A. para a avaliação dos resultados dos trabalhos de assistência técnica para a implantação da Reforma são os seguintes:

\section{“1. MOTIVAÇÃo do CLIENTE}

Oferecer assistência técnica aos clientes que apresentem seguras evidências de viabilidade de aproveitamento, em função de fatôres motivacionais e outros.

\section{VINCULAÇÃO A PROGRAMAS PRIORITÁRIOS} Oferecer assistência técnica preferentemente aos órgãos responsáveis por programas e projetos prioritários de desenvolvimento sócio-econômico do País, de acôrdo com as definições nas "Metas e Bases para a Ação de Govêrno" e nos planos em que estas se desdobrarem.

\section{ENFOQUE NA REMOÇÃO DE OBSTACULOS} INSTITUCIONAIS

Orientar inicialmente o trabalho de assistência técnica para a clarificação e remoção, a curto e médio prazos, dos obstáculos institucionais específicos que se apresentem na execução de programas e projetos prioritários de desenvolvimento sócio-econômico.

\section{ATUAÇÃo ATRAVÉS DO SISTEMA DE PLANEJAMENTO E ORÇAMENTO}

Prestar assistência técnica através dos setores ou equipes de planejamento e orçamento dos órgãos, atuando principalmente junto às Secretarias Gerais dos Ministérios, e exercendo influência no sentido que se fortaleça o sistema de planejamento e orçamento, bem como se integrem, em caráter permanente, o planejamento substantivo e o planejamento institucional (reforma administrativa).

6 E. R. A., "Avaliação dos Resultados da Reforma Administrativa", Convênio MPCG-ERA-FGV. no 1 , de 14-4-1971. 


\section{ATUAÇÃO EDUCATIVA}

Prestar assistência técnica com ênfase no processo educativo, evitando as práticas prescritivas e impositivas, mas orientando e motivando o pessoal do órgão assistido, principalmente 0 do sistema de planejamento e orçamento e as chefias de todos os níveis, para que êle próprio faça a reforma, e assim internalize os valôres, atitudes e comportamentos propícios à manutenção do processo de planejamento institucional com vistas à contínua modernização da máquina administrativa e sua adequação às necessidades do desenvolvimento acelerado do Brasil.

\section{DESENVOLVIMENTO DO PESSOAL}

Dedicar atenção especial à identificação das necessidades específicas de desenvolvimento dos recursos humanos do órgão assistido, em função dos pré-requisitos para implementação eficaz e eficiente de seus programas e projetos prioritários, e influir no sentido de que o treinamento do pessoal se oriente pragmática e funcionalmente, na maior extensão possível, para a execução dos programas e projetos concretos a cargo do órgão.

\section{ATENÇÃO AOS FATÔRES AMBIENTAIS}

Orientar o trabalho de assistência técnica com base no conhecimento sistemático dos fatôres ambientais relevantes, objetivando a adequação de estratégias e táticas à situação, para garantir uma satisfatória meIhoria na execução dos programas e projetos prioritários a cargo do órgão assistido.

\section{ARTICULAÇĀO COM OS SISTEMAS DE ATIVIDADES AUXILIARES}

Influir no sentido de que as atividades de reforma em cada órgão assistido, quando se refiram a assuntos compreendidos pelos sistemas de atividades auxiliares, como os de planejamento, orçamento, pessoal, administração financeira, contabilidade, auditoria, estatísti$\mathrm{ca}$, serviços gerais e outros, sejam sempre tratados em têrmos das normas vigentes para o sistema e em articulação com o respectivo órgão central. 


\section{UTILIZAÇÃO DE RECURSOS COMUNITARIOS}

Promover a utilização de recursos locais, principalmente em relação a pessoas e instituições nos campos técnico, científico e educacional, governamentais ou privados, com o objetivo de fortalecer os meios para realização de tarefas de pesquisa, assessoramento, treinamento, planejamento e outras, associadas à implementação da Reforma Administrativa.

\section{QUALIDADE E QUANTIDADE DO PESSOAL DE ASSISTENCIA TÉCNICA}

Assegurar pessoal de elevado padrão ético e técnicoprofissional e em quantidade adequada às necessidades de cada projeto.

\section{PROGRAMAÇÃO DOS TRABALHOS}

Prestar os serviços de assistência técnica sempre com base em programas de trabalho periódicos, elaborados mediante articulação entre os responsáveis pelo projeto no órgão assistido, na FGV e no ERA, e nos quais fiquem bem caracterizadas as tarefas, os respectivos prazos e responsáveis.

\section{ACOMPANHAMENTO CONSTRUTIVO}

Acompanhar e avaliar constantemente o trabalho de assistência técnica, por meio de observações diretas, contatos, reuniões, relatórios periódicos e outros meios, mantendo sempre uma atitude construtiva e cooperativa no sentido de contribuir para a melhoria dos serviços prestados ao cliente e para o êxito do projeto, com o máximo de aproveitamento dos recursos disponiveis para o programa de assistência técnica.

\section{ARTICULAÇÃO CLIENTE-FGV-ERA}

Manter constante comunicação entre os responsáveis pelo projeto no órgão assistido, na FGV e no ERA, e entre os respectivos superiores hierárquicos, de modo a se removerem, em tempo oportuno, quaisquer dificuldades que possam surgir no andamento dos trabalhos de assistência técnica. 


\section{MANUTENÇÃO DE RELAÇÕES HARMÔNICAS}

Assegurar relações harmônicas entre o pessoal da assistência técnica e o do órgão assistido.

\section{MANUTENÇÃO DE SIGILO}

Assegurar que o pessoal da assistência técnica mantenha o indispensável sigilo com relação às informações que obtiverem durante seus trabalhos.

16. INICIATIVA DE DIVULGAÇÃO SÔBRE A REFORMA ADMINISTRATIVA

Assegurar que a divulgação sôbre a Reforma Administrativa seja, em princípio, feita através do órgão assistido, quando o assunto a êle se referir, ou do Secretário Geral do Ministério do Planejamento e Coordenação Geral, nos demais casos."

Em suma, pretende-se estabelecer no Brasil uma administração racional e dinâmica, em contínuo processo de adaptação às realidades cambiantes e, acima de tudo, perfeitamente apta para coadjuvar poderosamente no desenvolvimento acelerado do País, que constitui hoje um imperativo categórico para a própria sobrevivência das instituições.

Ainda é muito cedo, òbviamente, dado o pouquíssimo tempo decorrido da adoção da nova dinâmica de implantação da Reforma Administrativa Brasileira, para dizer de seus resultados.

Tudo indica, porém, que êstes serão os mais auspiciosos, pois a nova dinâmica procura conjugar a capacidade técnica da Fundação Getúlio Vargas ao interêsse do órgão a ser reformado e ao apoio do E.R.A. e do Ministério do Planejamento e Coordenação Geral.

7 E.R.A., "Avaliação do Programa de Assistência Técnica", Convênio MPCG-ERA-FGV no 2, de 14-4-71). 


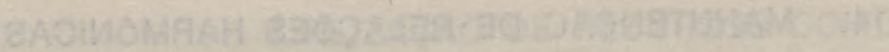

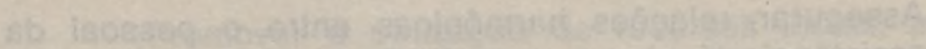

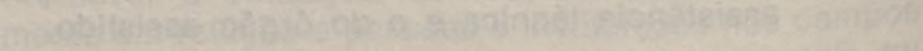

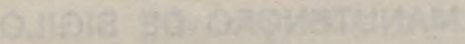

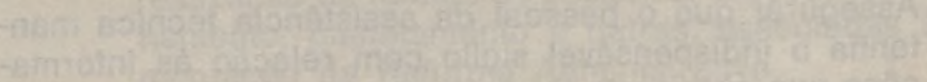

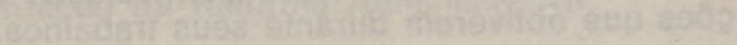

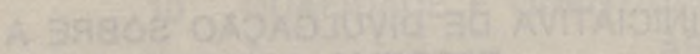

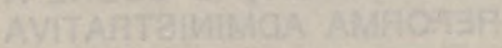

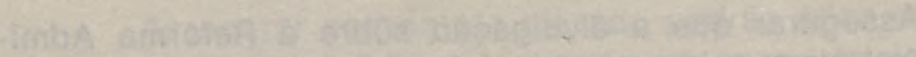

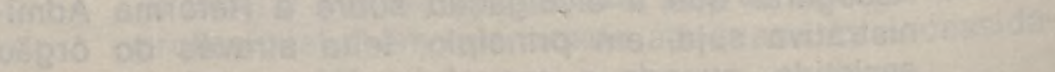

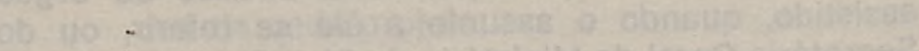

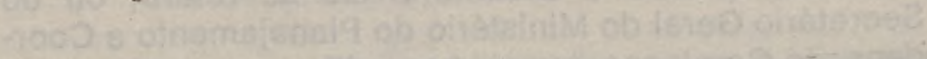

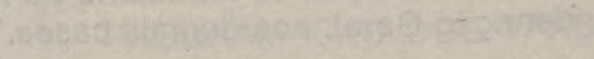

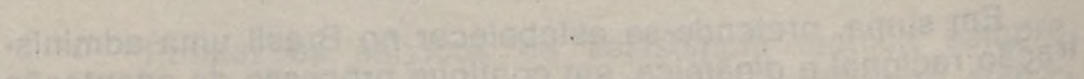

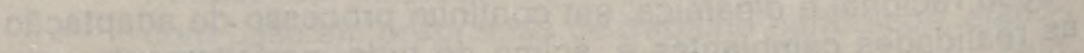

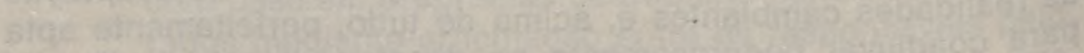

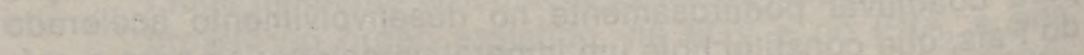

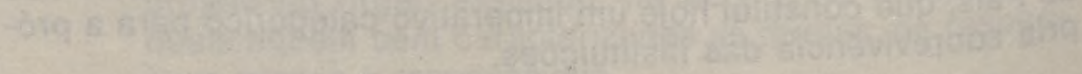

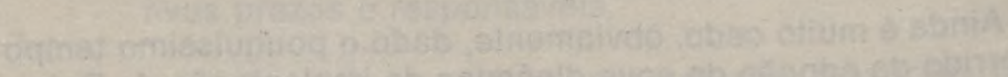

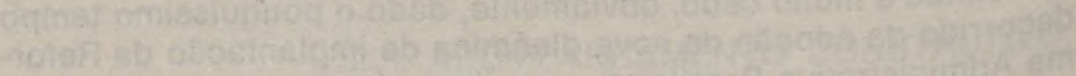

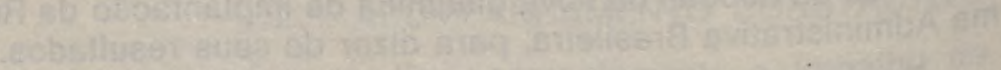

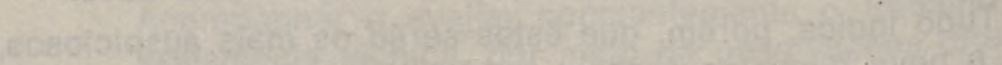

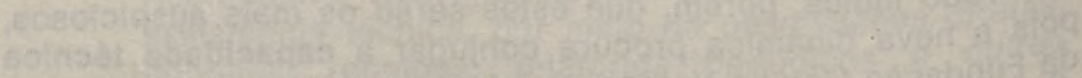

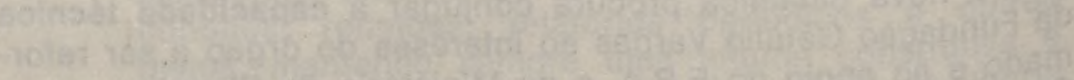

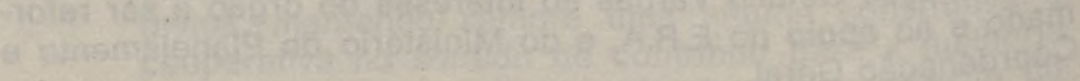

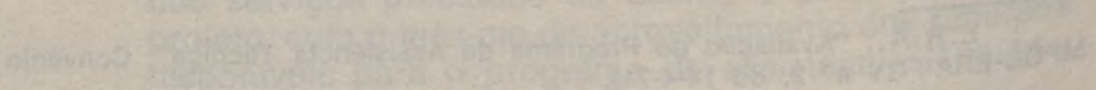

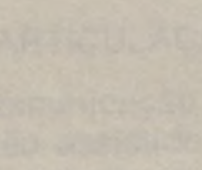

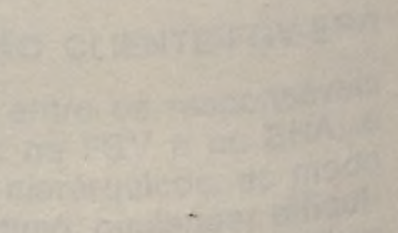

